at level of posterior major marginal seta. Pores fewer again on the last several plates.

Sternite of pregenital segment broad, trapeziform. Coxopleural glands two on each side, simple, the pores covered by the sternite.

Last legs in the male clavately enlarged, scarcely exceeding the penult in length. Unfortunately these became detached and lost in the course of the clearing of the specimen for mounting for microscopical study.

Number of pairs of legs in the male, thirty-five.

Length of the type, $7.5 \mathrm{~mm}$.

It is thought best not completely to dissect the head of the single type specimen at this time. Hence mandibles and maxillæ are not described in detail.

\title{
PROCEEDINGS OF THE CAMBRIDGE ENTOMOLOGICAL CLUB.
}

At the meeting of the Cambridge Entomological Club February 10 , on account of the difficulties of travel only 14 persons attended. The meeting voted to approve the publication, in Psyche, of abstracts of the proceedings of the Club meetings and of local entomological news.

Prof. C. T. Brues read some notes on distribution of South African Hymenoptera, several of which occur or have their nearest relatives in South America or India rather than in more northern parts of Africa. Professor Wheeler read a satire on human society from the supposed standpoint of a member of a colony of Termites. This paper is published in the Scientific Monthly of February, 1920.

Mr. Varás showed a beetle with a branched tibia of one of the third pair of legs, and this was followed by discussion of abnormal insert legs in general.

At the meeting of March 9, Mr. J. H. Emerton read some notes on last season's collections of spiders in Canada, including specimens from the Rocky Mountains, near Banff, Pribiloff Islands, Klondike Valley, Gaspe, St. John's, Newfoundland, Ontario and Quebec.

Mr. Frost read notes on the habits, occurrence and classification of several Coleoptera which he had found in Maine-Scythropus elegans, cicendela elegans and cicendela spreta Lecr. The latter species he thought to be the same as C. limbalis Klug. 

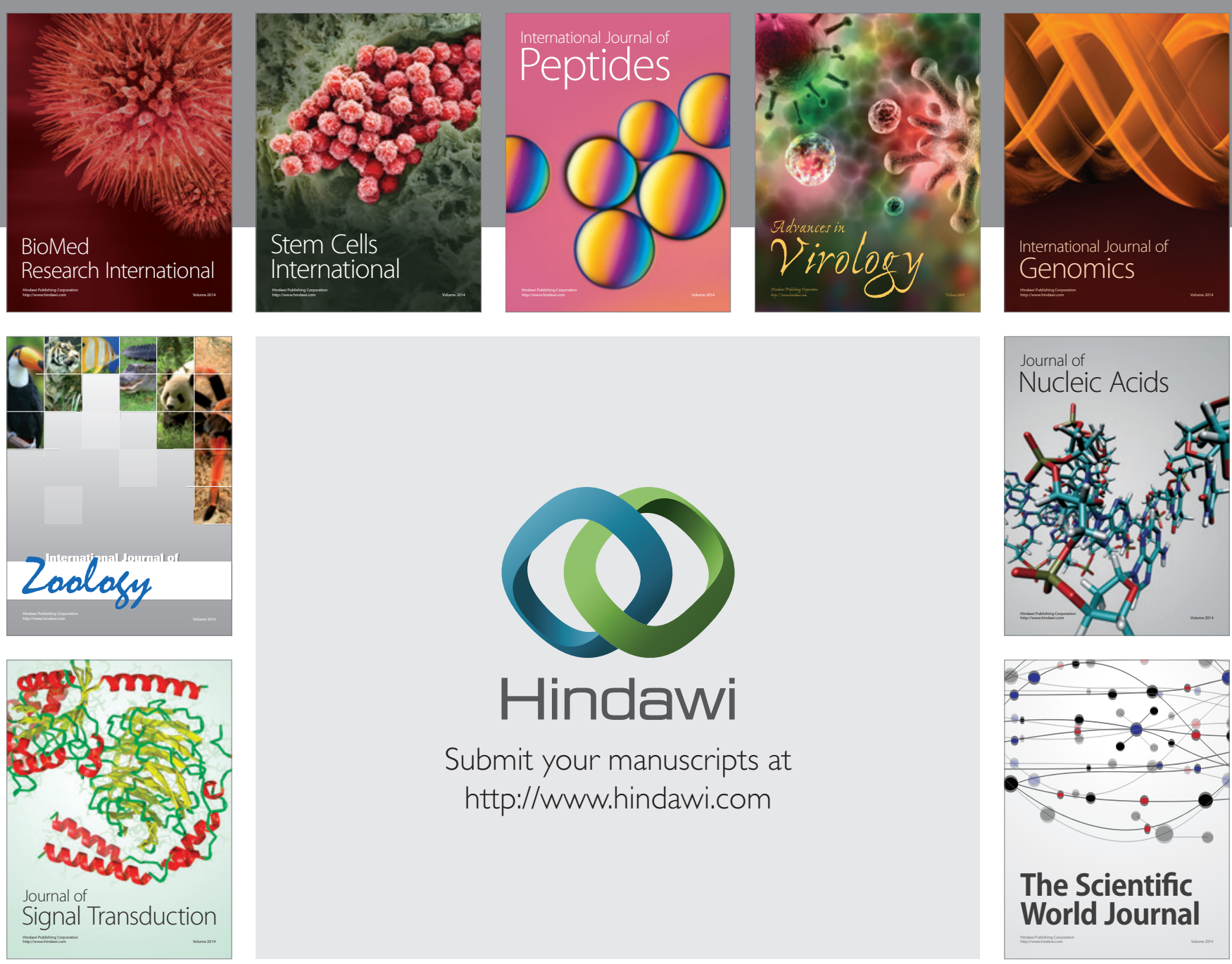

Submit your manuscripts at

http://www.hindawi.com
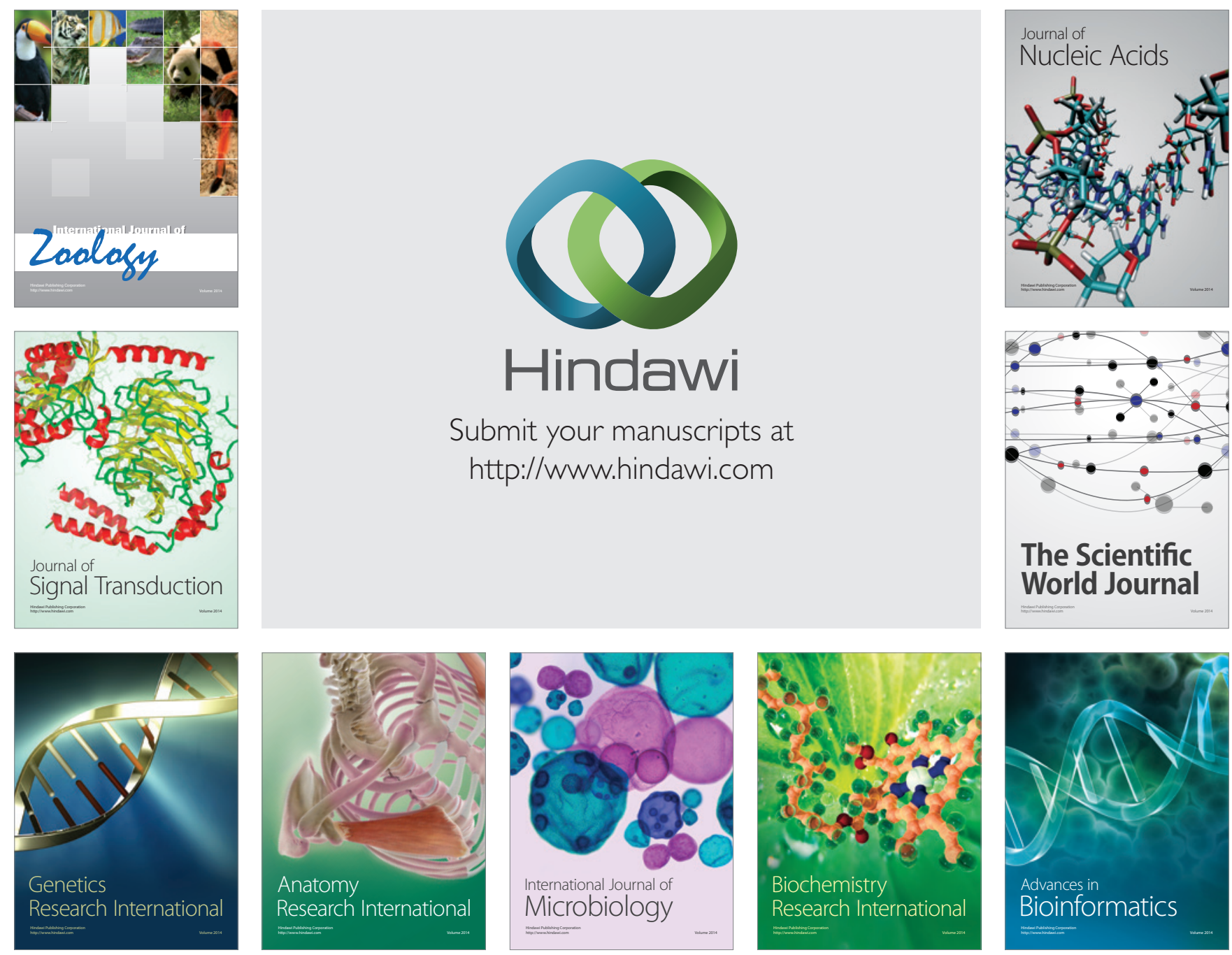

The Scientific World Journal
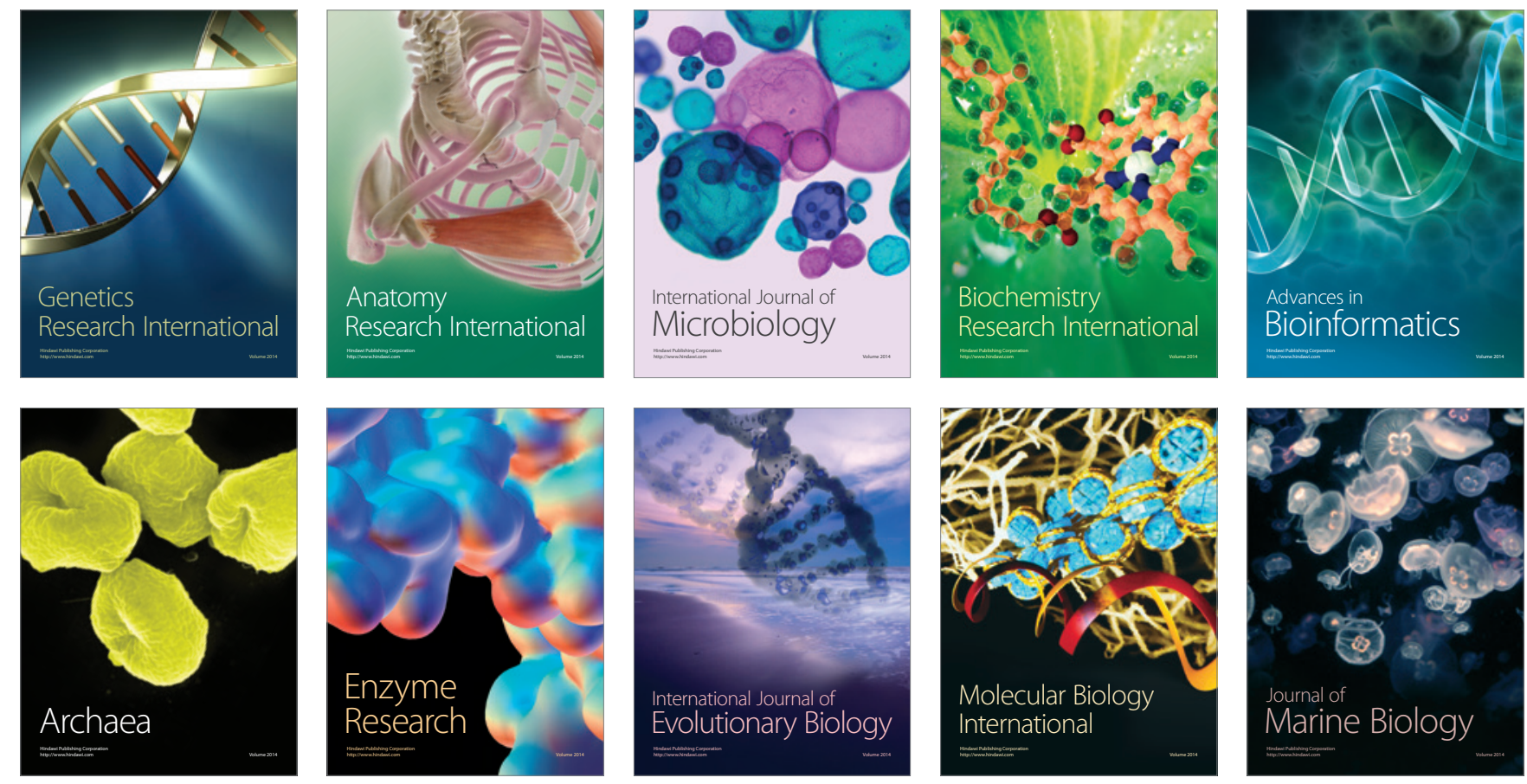